University of Nebraska - Lincoln

DigitalCommons@University of Nebraska - Lincoln

\title{
Insect-Attracting and Antimicrobial Properties of Antifreeze for Monitoring Insect Pests and Natural Enemies in Stored Corn
}

\author{
Xinzhi Ni \\ USDA-ARS, xinzhi.ni@ars.usda.gov \\ Gunawati Gunawan \\ University of Georgia \\ Steve L. Brown \\ University of Georgia \\ Paul E. Sumner \\ University of Georgia \\ John R. Ruberson \\ University of Georgia, jruberson2@unl.edu \\ See next page for additional authors
}

Follow this and additional works at: https://digitalcommons.unl.edu/usdaarsfacpub

Ni, Xinzhi; Gunawan, Gunawati; Brown, Steve L.; Sumner, Paul E.; Ruberson, John R.; Buntin, G. David; Holbrook, C. Corley; Lee, R. Dewey; Streett, Douglas A.; Throne, James E.; and Campbell, James F., "InsectAttracting and Antimicrobial Properties of Antifreeze for Monitoring Insect Pests and Natural Enemies in Stored Corn" (2008). Publications from USDA-ARS / UNL Faculty. 2015.

https://digitalcommons.unl.edu/usdaarsfacpub/2015

This Article is brought to you for free and open access by the U.S. Department of Agriculture: Agricultural Research Service, Lincoln, Nebraska at DigitalCommons@University of Nebraska - Lincoln. It has been accepted for inclusion in Publications from USDA-ARS / UNL Faculty by an authorized administrator of DigitalCommons@University of Nebraska - Lincoln. 


\section{Authors}

Xinzhi Ni, Gunawati Gunawan, Steve L. Brown, Paul E. Sumner, John R. Ruberson, G. David Buntin, C. Corley Holbrook, R. Dewey Lee, Douglas A. Streett, James E. Throne, and James F. Campbell 


\title{
Insect-Attracting and Antimicrobial Properties of Antifreeze for Monitoring Insect Pests and Natural Enemies in Stored Corn
}

\author{
XINZHI NI ${ }^{1,2}$ GUNAWATI GUNAWAN, ${ }^{3}$ STEVE L. BROWN, ${ }^{3}$ PAUL E. SUMNER, ${ }^{4}$ JOHN R. RUBERSON, ${ }^{3}$ \\ G. DAVID BUNTIN ${ }^{5}$ C. CORLEY HOLBROOK, ${ }^{1}$ R. DEWEY LEE ${ }^{6}$ DOUGLAS A. STREETT, ${ }^{7}$ \\ JAMES E. THRONE, ${ }^{8}$ AND JAMES F. CAMPBELL ${ }^{8}$
}

\begin{abstract}
J. Econ. Entomol. 101(2): 631-636 (2008)
ABSTRACT Insect infestations in stored grain cause extensive damage worldwide. Storage insect pests, including the Indianmeal moth, Plodia interpunctella (Hübner) (Lepidoptera: Pyralidae); Sitophilus spp. (Coleoptera: Curculionidae); and their natural enemies [e.g., Cephalonomia tarsalis (Ashmead) (Hymenoptera: Bethylidae), and Anisopteromalus calandrae (Howard) (Hymenoptera: Pteromalidae) ] inhabit a temporary, but stable ecosystem with constant environmental conditions. The objective of the present experiment was to assess the efficacy of using ethylene glycol antifreeze in combination with nutrient solutions to monitor storage insect pest and natural enemy populations in three bins of corn, Zea mays $\mathrm{L}$. The treatments were deionized water, a diluted (1:5 antifreeze:water) antifreeze solution, $10 \%$ honey, $10 \%$ honey in the diluted antifreeze solution, $10 \%$ beer in the diluted antifreeze solution, $10 \%$ sucrose in the diluted antifreeze solution, and a commercial pheromone trap suspended in a 3.8-liter container filled with $300-\mathrm{ml}$ of diluted antifreeze solution. The seven treatments captured storage insect pests and their natural enemies in the bins at $33-36^{\circ} \mathrm{C}$ and $51-55 \% \mathrm{RH}$. The pheromone trap in the container with the diluted antifreeze captured significantly more $P$. interpunctella than the other treatments, but a lower percentage $(7.6 \%)$ of these captures were females compared with the rest of the treatments ( $>40 \%$ females). All trapping solutions also captured Sitophilus spp. and other beetle species, but the captures of the coleopteran pests were not significantly different among the seven treatments $(P>0.05)$. Two parasitoid wasps also were captured in the study. The number of $A$. calandrae was different among the seven treatments $(P<$ $0.05)$, whereas the number of $C$. tarsalis was not different among the treatments $(P>0.05)$. Most $A$. calandrae adults were captured by the $10 \%$ honey in the diluted antifreeze, whereas the fewest were captured in the deionized water. Microbial growth was observed in the $10 \%$ honey solution, but no microbial growth occurred in the rest of the treatments, including $10 \%$ honey in the diluted antifreeze solution. The results of insect captures and microbial growth demonstrated that antifreeze could be used as a part of storage insect monitoring and/or control programs.
\end{abstract}

KEY WORDS trapping, ethylene glycol, Plodia interpunctella, Sitophilus spp., parasitoid

Infestations by stored-product insect pests can cause significant economic losses in raw and processed commodities worldwide (Hagstrum et al. 1999). Levels of

Mention of trade names or commercial products in this article is solely for the purpose of providing specific information and does not imply recommendation or endorsement by the U.S. Department of Agriculture.

${ }^{1}$ USDA-ARS, Crop Genetics and Breeding Research Unit, Tifton, GA 31793-0748.

${ }^{2}$ Corresponding author, e-mail: xinzhi.ni@ars.usda.gov.

${ }^{3}$ Department of Entomology, University of Georgia, Tifton, GA 31793-0748.

${ }^{4}$ Department of Biological and Agricultural Engineering, University of Georgia, Tifton, GA 31793-0748.

${ }^{5}$ Department of Entomology, University of Georgia, Griffin, GA 30223-1797.

${ }^{6}$ Department of Plant Soil Sciences, University of Georgia, Tifton, GA 31793-0748.

${ }^{7}$ USDA-ARS, Biological Control of Pests Research Unit, Stoneville, MS 38776.

${ }^{8}$ USDA-ARS, Biological Research Unit, USDA-ARS Grain Marketing and Production Research Center, Manhattan KS 66502-2736. insect infestations in processing and storage facilities are generally monitored using pheromone-baited traps (Phillips 1994, 1997). Use of pheromone/food odor traps to monitor insects in commercial food storage and processing environments is increasing, and a range of attractants and trap types are available (Phillips et al. 2000). However, mass pheromone trapping has yielded only limited success as a management strategy for insect pests of stored products (Phillips 1997, Reichmuth 1999, Shani and Clearwater 2001). Most pheromone traps for moths are designed to use female-emitted attractive components to attract males, but the polygamous nature of the remaining untrapped males of some species generally negate any benefits derived from the trapping. Traps that attract females or both sexes are essential to effectively reduce pest populations. The use of food odor as attractants and in combination with pheromones for trapping both males and ovipositing females have 
been investigated for controlling insect pests of stored products (Phillips 1997). However, most of these food attractants are derived from stored products; thus, they need to compete with food odors already present in a food facility and they have had limited effectiveness as a control. Water has been shown to be attractive to females of Cadra (Ephestia) cautella (Walker) (Lepidoptera: Pyralidae), but other moth species were not responsive (Chow et al. 1977; Ryne et al. $2002,2004)$. In general, improvement in the efficacy of mass adult trapping as a pest management tactic for these insect species remains limited.

Ni and Holbrook (2006) reported that a $10 \%$ honey solution effectively captured the same number of $C$. cautella as a commercial pheromone trap in a peanut (Arachis hypogaea L.) shelling and storage facility. Of the total number of C. cautella captured in the experiment, $70 \%$ were females in the honey solution, whereas only $20 \%$ females were captured in pheromone-baited traps. However, the loss of water in the trapping containers and mold growth in nutrient solution might have negatively affected the trapping efficiency. A preliminary study indicated that the addition of antifreeze in the trapping containers could synergistically improve capture of C. cautella in the peanut shelling facility in three different ways: 1) reducing water evaporation, 2) eliminating mold growth in nutrient solutions, and 3) serving as an attractant in and of itself (X.N., unpublished data). The objective of the current study was to examine the efficacy of using antifreeze in combination with nutrient solutions to trap stored-product insect pests and their natural enemies in corn, Zea mays L., grain bins.

\section{Materials and Methods}

Facility Location. Three bins (5-metric ton capacity) filled with 1 metric ton of corn naturally infested with storage insects on the Animal and Dairy Science Research Farm at the University of Georgia-Tifton Campus, Tifton, GA, were used to conduct this experiment. The bins were located at $31.5 \mathrm{~N}, 83.5 \mathrm{~W}$ in a subtropical climate. The experiment was conducted during a 4 -wk period between 22 June and 20 July 2006. The facility temperature and humidity were recorded weekly for every bin by placing a digital thermo-hygro-meter (VWR, Bridgeport, NJ) on the top surface of the corn where the traps were placed.

Insect Infestation in the Bins. The corn in the three grain bins was harvested in August 2005 from fields near Tifton, GA. The grain used in the study was not treated with insecticide since its harvest in August 2005. Natural infestations of storage insect pests and their natural enemies were detected before the initiation of the experiment. A survey for insect fauna before the experiment showed that insect pests in the stored corn included the Indianmeal moth, Plodia interpunctella (Hübner) (Lepidoptera: Pyralidae); Sitophilus spp. (Coleoptera: Curculionidae); sawtoothed grain beetle, Oryzaephilus surinamensis (L.) (Coleoptera: Silvanidae); and flour beetles Tribolium spp. (Coleoptera: Tenebrionidae), which supported the description of stored grain pest species in the southeastern United States by Arbogast and Throne (1997). Two species of parasitoid wasp found in the stored corn were Cephalonomia tarsalis (Ashmead) (Hymenoptera: Bethylidae) and Anisopteromalus calandrae (Howard) (Hymenoptera: Pteromalidae).

Treatments. In the previous study, the $10 \%$ honey solution was the best for trapping a high percentage of female C. cautella and had the most serious mold problem (Ni and Holbrook 2006). We included only two of the previously tested treatments (i.e., deionized water $\left[\mathrm{dH}_{2} \mathrm{O}\right]$ and $10 \%$ honey solution treatments) with or without addition of antifreeze in the present experiment. An additional three treatments (beer, sucrose, and pheromone trap) in combination with antifreeze also were examined to evaluate the impact of antifreeze on insect captures. Thus, the seven treatments were 1) $\left.\mathrm{dH}_{2} \mathrm{O} ; 2\right) \mathrm{dH}_{2} \mathrm{O}$ with a diluted (1:5 vol:vol) antifreeze (Prestone antifreeze [Prestone Products Corp., Danberry, CT] containing ethylene and diethylene glycol) solution; 3 ) 10\% (wt: vol) honey (Great Value clover honey [Wal-Mart, Inc., Bentonville, AR [rqsb]) solution; 4) $10 \%$ honey (wt:vol) in a diluted (1:5 vol:vol) antifreeze solution; 5) $10 \%$ (wt:vol) beer (Miller Lite beer [Miller brewing Co., Milwaukee, WI]) in the diluted antifreeze solution (1:5 vol:vol);6) 10\% (wt:vol) sucrose [Fisher, St. Louis, MO] in the diluted antifreeze solution (1:5 vol:vol); and 7) a suspended pheromone trap (XlureR.T.U., Russell IPM, Deeside, United Kingdom) with the diluted antifreeze solution (1:5 vol:vol) in a 3.8liter container. The commercial pheromone trap was a sticky trap in a diamond shape designed to trap Plodia and Cadra moths. All nutrient solutions were made with the deionized water from a model E-Pure Barnstead Water System (Dubuque, IA).

Trap Design. All traps were placed on top of the grain surface in a circle with $\approx 1.5 \mathrm{~m}$ between any two adjacent traps in each bin. Traps consisted of $300 \mathrm{ml}$ of experimental treatment solution in a 3.8-liter white cylindrical ice cream container $(20 \mathrm{~cm}$ in height, $20 \mathrm{~cm}$ in diameter at top, and $17 \mathrm{~cm}$ in diameter at bottom) (Berry Plastics, Evansville, IN) without lids or any other modification. The deionized water was used to reduce microbial growth in the container. Each trapping session lasted for $7 \mathrm{~d}$, and each of the three grain bins was considered a replications. The weekly trapping experiment was repeated four times (or lasted 4 wk), which were considered four trials of the experiment. Traps were replaced weekly, and trap location in the bins was rerandomized each week.

Insect Identification. All insects collected during the experiment were identified based on the keys of Delinger and Davis (1982) and USDA-ARS (1986). The total number of each insect taxon or guild (i.e., Indianmeal moth, Sitophilus spp., other beetle species, and parasitoid wasps) was identified and recorded for further analysis, and sex of the moths was determined using presence of scent brush at the end of the abdomen of the males (Chapman 1982). Insects from the sticky surface of the commercial pheromone traps were gently removed and identified. The Indianmeal 


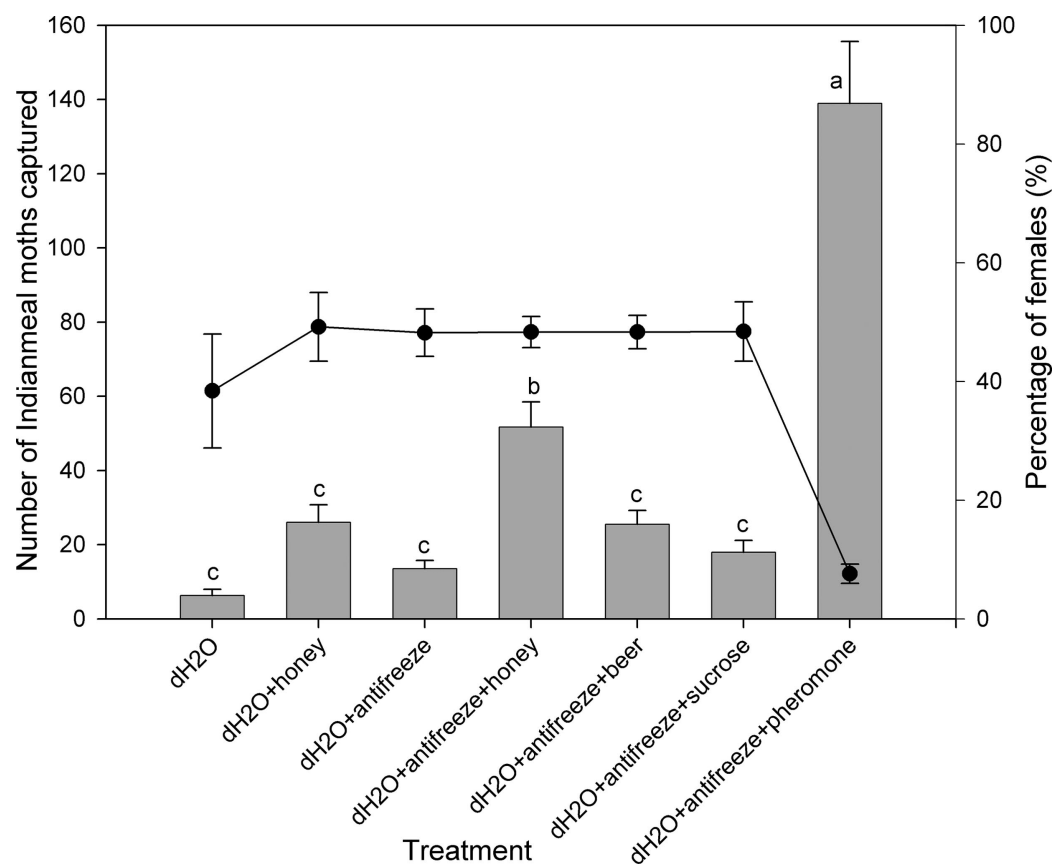

Fig. 1. Effect of the seven bait combinations on the number of the Indianmeal moths (bar graph) and percentage of females (line graph) captured in the three bins during a 4 -wk period $(n=12)$. The bars with different letters are significantly different $(P<0.05 ;$ LSD). The error bars denote SEM.

moths also were dissected to confirm sexes of the moths by differentiating reproductive systems using presence of ovariole versus testes. Voucher specimens were deposited at the University of Georgia's Collection of Arthropods, Athens, GA.

Microbial Growth in Trapping Solutions. The microbial growth (mainly a layer of mold) on the surface of the trapping solutions for the seven treatments was recorded using a facultative index of 0 for no growth, 1 for a layer of microbial growth observed on the surface of trapping solution, and 2 for heavy microbial growth with visible colonies of filamentous fungi. The colonies of the mold growing on different treatments were identified according keys described by St-Germain and Summerbell (1996). No further diagnostic identification of the microbes was conducted because the main purpose of the current study was to determine whether the antifreeze can be used to prevent mold growth in general.

Experimental Design, Data Collection, and Analysis. The experiment used a repeated measures design, because data were collected weekly throughout a period of $4 \mathrm{wk}$, and the three bins were considered replications for the experiment. The seven treatments were randomly arranged in each of the three bins. All insect and microbial growth data collected from the experiment were analyzed using the PROC GLM procedure for repeated measures analysis of variance as described in the SAS statistical software version 9.1 (SAS Institute 2003). Temperature and humidity data were compared among the three bins and the $4 \mathrm{wk}$ of the experimental period by using PROC GLM proce- dure. The means for all insect data were separated using Fisher-protected least significant difference (LSD) test $(\alpha=0.05)$.

\section{Results}

Temperature and Relative Humidity in Bins. The temperature and relative humidity was stable during the 4 -wk period. The temperature recordings were similar among the $4 \mathrm{wk}(F=0.49 ; \mathrm{df}=3,6 ; P=0.6997)$, and among the three bins $(F=2.58 ; \mathrm{df}=2,6 ; P=$ 0.1554 ). Average temperature ranged between 33.3 and $36.4^{\circ} \mathrm{C}$. $\mathrm{RH}$ also showed no difference either among the $4 \mathrm{wk}(F=0.13 ; \mathrm{df}=3,6 ; P=0.9391)$, nor among the three bins $(F=0.28 ; \mathrm{df}=2,6 ; P=0.7629)$. Average relative humidity ranged between 51.3 and $55.5 \%$.

Capture of Indianmeal Moths. The total number of Indianmeal moths was significantly $(F=9.98 ; \mathrm{df}=6$, $14 ; P=0.0002$ ) different among the seven treatments (Fig. 1). The capture of moths was not significantly $(F=2.18 ; \mathrm{df}=3,14 ; P=0.1045)$ different among the four weekly trappings.

The percentage of the female Indianmeal moths captured by the seven treatments was significantly $(F=5.92 ; \mathrm{df}=6,14 ; P=0.0029)$ different. The treatment with commercial pheromone lure and diluted antifreeze solution captured only $7.6 \%$ females, whereas water treatment captured $38 \%$, and the honey solution and the other four treatments with diluted antifreeze solution captured $48-49 \%$ females (Fig. 1). Further comparison between the $10 \%$ honey solution 


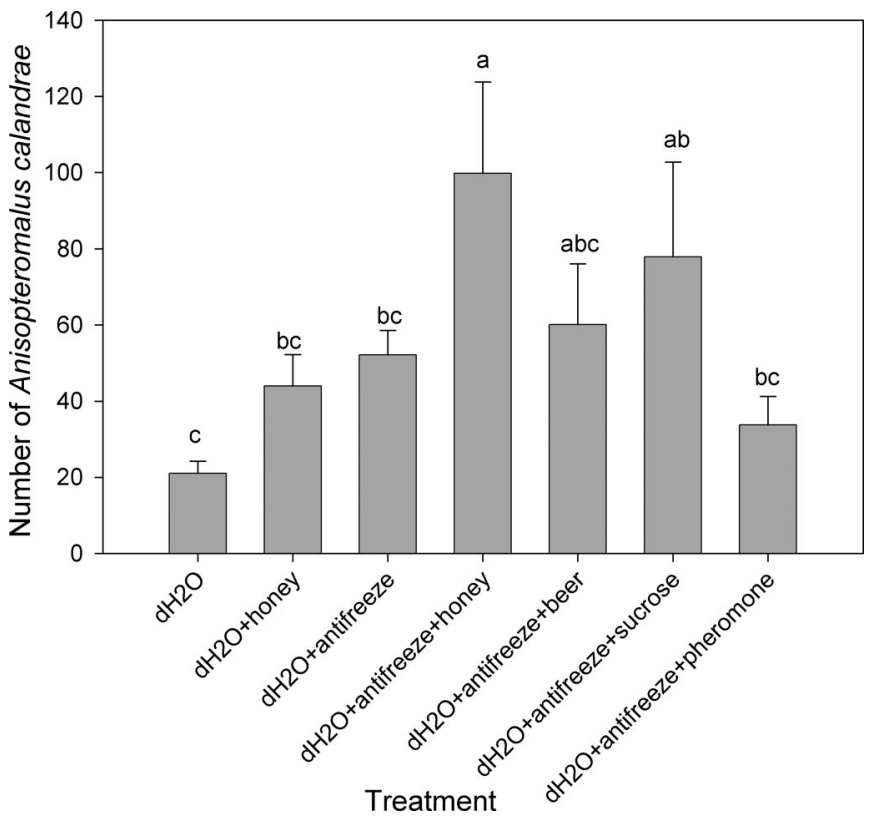
SEM

Fig. 2. Influence of the seven bait combinations on the number of A. calandrae captured $(n=12)$. The error bars denote

and $10 \%$ honey in diluted antifreeze solution showed that the addition of antifreeze significantly $(F=4.77$; df $=1,12 ; P=0.0078)$ increased moth captures; however, the female percentage was the same $(P=$ 0.9601 ) between the two treatments. Comparison between the diluted antifreeze solution and pheromone trap in container with the diluted antifreeze solution showed that addition of pheromone trap significantly $(F=618.69 ; \mathrm{df}=1,12 ; P=0.0251)$ increased total number of moths captured, and at the same time, the pheromone trap significantly reduced the percentage of female moth captures in the trapping container $(F=73.87 ; \mathrm{df}=1,12 ; P=0.0001)$. However, the number of female moths captured in the two treatments was similar; antifreeze solution captured six females of 14 moths, and addition of pheromone trap in antifreeze solution captured 10 females of 138 moths.

Capture of Beetles. The number of Sitophilus spp. attracted by the trapping solutions was not different $(F=0.22 ; \mathrm{df}=6,14 ; P=0.9652)$ among the seven treatments. The least number of Sitophilus spp. was captured by the diluted antifreeze solution $(4.6 \pm 1.4)$, and honey solution $(4.7 \pm 2.2)$, whereas the most number of the Sitophilus spp. was captured by the treatments of beer $(11.8 \pm 5.5)$ and honey $(10.8 \pm 4.4)$ in antifreeze solutions (data are not shown, because no significant difference was detected). Similarly, the capture of storage grain beetles (i.e., total number of beetles excluding Sitophilus spp.) was not different $(F=0.37, \mathrm{df}=6,14, P=0.8840)$ among the seven treatments. The minimum number of the grain beetles was captured by the treatments of deionized water $(7.6 \pm 1.8)$ and $10 \%$ honey solution $(7.3 \pm 2.5)$, whereas the maximum number of grain beetles was captured by the treatment of beer in the diluted antifreeze solution $(16.3 \pm 5.2)$ and the pheromone trap in combination with antifreeze solution $(11.6 \pm 2.3)$.

Capture of Parasitoid Wasps. The attraction of the parasitoid wasps varied. The number of $A$. calandrae captured by the seven treatments was significantly different $(F=6.52$; df $=6,14 ; P=0.0019)$ among treatments (Fig. 2), whereas the number of $C$. tarsalis was not different $(F=0.35 ; \mathrm{df}=6,14 ; P=0.9012)$ among treatments. The addition of honey in antifreeze solution increased captures of A. calandrae, whereas the least number of the wasps were captured in the deionized water treatment (Fig. 2). In contrast, the addition of antifreeze in honey solution only attracted one-sixths of the number of $C$. tarsalis $(16.7 \pm 2.9)$ compared with A. calandrae. The control treatment (water only) also attracted approximately only one third as many $C$. tarsalis $(7.2 \pm 1.3)$ as A. calandrae.

Microbial Growth. Levels of microbial growth were significantly different $(F=36.57$, df $=6,14, P=$ 0.0001 ) among the seven treatments. Microbial growth was only observed on $10 \%$ honey solution but not on any of the other six treatments. The paired comparison between $10 \%$ honey and $10 \%$ honey in diluted antifreeze solution showed that addition of antifreeze in 1:5 (vol:vol) ratio effectively $(F=153.60$; $\mathrm{df}=1,12 ; P=0.0001$ ) eliminated fungal growth in the 7 -d monitoring period.

\section{Discussion}

Sweet baits and antifreeze have been examined as trapping ingredients in recent years (Landolt 1995, Ni and Holbrook 2006, Robacker and Czokajlo 2006). Molasses and unfinished palm sugar (also known as 
jaggery) significantly increased capture of Mocis latipes Guenee (Lepidoptera: Noctuidae) (Landolt 1995), and a $10 \%$ honey captured $>70 \%$ female $C$. cautella moths (Ni and Holbrook 2006). Although antifreeze was originally used in traps to preserve insects captured in the traps, Thomas et al. (2001) found that addition of antifreeze in water doubled the capture of feral Mexican fruit fly, Anastrepha ludens (Loew) (Diptera: Tephritidae). Robacker and Czokajlo (2006) reported the addition of water with propylene glycol antifreeze as the drowning agent was $\approx 2$ times more attractive than the traps baited with the lures made by Advanced Pheromone Technologies, Marylhurst, OR.

At present, pheromone traps are widely used in storage facilities for mainly monitoring purposes with limited success as a population control tool (Phillips 1997, Shani and Clearwater 2001, Ni and Holbrook 2006). In the current study, the capture of $48-49 \%$ female Indianmeal moths at $35^{\circ} \mathrm{C}$ and $50 \% \mathrm{RH}$ in bins of corn is of potential importance for storage insect management in the subtropical environment. This finding supports the previous report by $\mathrm{Ni}$ and Holbrook (2006) that nutrient solutions could be used to effectively attract lepidopteran (in particular, pyralid) females in storage facilities. The comparison between $10 \%$ honey solution and $10 \%$ honey in diluted antifreeze solution showed that the addition of antifreeze in nutrient solutions also increased the capture of Indianmeal moths. Without it, the honey solution was not any more effective than the water treatment, suggesting that the high temperature conditions lead to rapid degradation of the honey solution (indicated by the high mold growth in that treatment). Furthermore, addition of pheromone trap in a diluted antifreeze container greatly increased the percentage of male moths from 51.8 to $92.4 \%$. Water or water and soap solutions have been shown to be attractive to the stored-product moth C. cautella (Chow et al. 1977, Ryne et al. 2002), but this experiment showed that water alone was not very attractive to the Indianmeal moth. However, the moth captures had a high female/ male sex ratio compared with the pheromone treatment, suggesting a stronger female response when water was present. Nansen et al. (2004) reported that the height and adjacent surface of pheromone traps also affected the capture of Indianmeal moths. The effect of pheromone trap height on the efficacy of traps using nutrients in diluted antifreeze solutions should be examined in future studies, which might, in return, increase the efficacy of overall storage insect trapping. Sweeney et al. (2006) demonstrated that propylene glycol as part of the killing agents increased the capture of Tetropium fuscum (F.) and other related species (Coleoptera: Cerambycidae). The findings from the current study indicated that the coleopteran insects could be attracted to liquid trapping solutions, but no significant difference was detected among the seven treatments. Thus, the beetles present in these bins did not seem to respond preferentially to the honey solution, as did the moths, nor did they respond to antifreeze (containing ethylene and diethylene gly- col) directly, because the water alone treatment was not significantly different from any of the treatments with antifreeze.

In the current experiment, the honey solution without antifreeze was a nutritious medium for fungal growth in the grain bins. Mold growth was recorded in $10 \%$ honey solution within a period of $7 \mathrm{~d}$, but not in any nutrient solutions with the addition of antifreeze. Thus, antifreeze not only prevents loss of water in trapping nutrient solutions and preserves insect specimens but also prevents mold growth in nutrient solutions, which may extend the period of efficacy of these traps. The possibility of using ethylene glycol alternatives (e.g., glycerol [Ni and Streett 2005] or propylene glycol [Robacker and Czokajlo 2006]) for microbial control in these nutrient solutions to be used for storage insect monitoring should be further examined.

The current study also demonstrated a potential negative consequence of this type of trapping in that some parasitoid wasp species also were captured in large numbers. However, we could take advantage of such effectiveness, and use the technique for only $24 \mathrm{~h}$ (instead of $7 \mathrm{~d}$ ) to monitor natural enemy population dynamics in stored products with reduced removal of the natural enemy populations. Among all seven treatments, the $10 \%$ honey in diluted antifreeze solution attracted the most $A$. calandrae $(99.8 \pm 24)$, whereas the deionized water captured the least $A$. calandrae $(21 \pm 3.2)$. In contrast, the capture of $C$. tarsalis was not different among the seven treatments. However, there was not a significant preference for the honey over other nutrient antifreeze combinations tested. The difference in the number of the two parasitoid wasps captured in this experiment could be caused by either difference in wasp populations in the grain bins or no preference of $C$. tarsalis shown among the seven trapping treatments.

In conclusion, the mixture of nutrients (i.e., honey, beer, and sugar) in diluted antifreeze could be used as an effective measure to monitor and possibly manage storage insects, such as, lepidopteran and coleopteran pests without mold growth in the nutrient solutions. The trapping technique is also effective in trapping hymenopteran parasitoids (in particular, A. calandrae) of storage insect pests in grain bins. The Indianmeal moth is not only a pest in stored corn but also the most important pest of stored processed commodities in warehouses and retail outlets. The ability of this economic mixture of antifreeze and honey solution to work in environments with competing food odors is especially interesting and the potential for long-term pest population suppression merits further examination.

\section{Acknowledgments}

We thank M. McDaniel, H. Hilton, J. C. Mullis, and K. Marchant (Crop Genetics and Breeding Research Unit, USDA-ARS, Tifton, GA) for assistance in conducting the experiment. We also express our gratitude to J. Davis (University of Georgia-Griffin) for advice on data analysis. We are 
indebted to A. N. Sparks, Jr., and M. D. Toews (Department of Entomology, University of Georgia-Tifton) for constructive comments on earlier drafts of the manuscript. We appreciate the financial support from the Georgia Corn Commission to conduct this experiment.

\section{References Cited}

Arbogast, R. T., and J. E. Throne. 1997. Insect infestation of farm-stored maize in South Carolina: towards characterization of a habitat. J. Stored Prod. Res. 33: 187-198.

Chapman, R. F. 1982. The insects: structure and function. Harvard University Press, Cambridge, MA.

Chow, Y. S., D. F. Yen, and S. H. Lin. 1977. Water, a powerful attractant for the gravid females of Plodia interpunctella and Cadra cautella. Experientia 15: 453-455.

Delinger, L. M., and R. Davis. 1982. Insect control in postharvest peanuts, pp. 521-570. In H. E. Pattee and C. T. Young [eds.], Peanut science and technology. American Peanut Research and Education Society, Yoakum, TX.

Hagstrum, D. W., C. Reed, and P. Kenkel. 1999. Management of stored wheat insect pests in the USA. Integr. Pest Manag. Rev. 4: 127-142.

Landolt, P. J. 1995. Attraction of Mocis latipes (Lepidoptera: Noctuidae) to sweet baits in traps. Fla. Entomol. 78: 523-530.

Nansen, C., T. W. Philips, and S. Sanders. 2004. Effects of height and adjacent surfaces on captures of Indianmeal moth (Lepidoptera: Pyralidae) in pheromone-baited traps. J. Econ. Entomol. 97: 1254-1260.

$\mathrm{Ni}, \mathrm{X}$., and C. C. Holbrook. 2006. Using nutrient solutions to trap the almond moth (Lepidoptera: Pyralidae) in a peanut shelling and storage facility. J. Entomol. Sci. 41: 285291.

Ni, X., and D. A. Streett. 2005. Modulation of water activity on fungicide effect on Aspergillus niger growth in Sabouraud dextrose agar medium. Lett. Appl. Microbiol. 41: $428-433$.

Phillips, T. W. 1994. Pheromones of stored-product insects: current status and future perspectives, pp. 479-486. In E. Highley, E. J. Wright, H. J. Banks, and B. R. Champ [eds.], Proceedings of the Sixth International Working Conference on Stored-Product Protection, vol. 1. CAB International, Wallingford, United Kingdom.
Phillips, T. W. 1997. Semiochemicals of stored-product insects: research and applications. J. Stored Prod. Res. 33: 17-30.

Phillips, T. W., R. C. Berberet, and G. W. Cuperus. 2000. Postharvest integrated pest management, pp. 2690-2701. In F. J. Francis [ed.], The Wiley encyclopedia of food science technology, 2nd ed., Wiley, New York.

Reichmuth, C. O. 1999. Trends in stored-product protection-the German perspective. Phytoparasitica 27: 3-7.

Robacker, D. C., and D. Czokajlo. 2006. Effect of propylene glycol antifreeze on captures of Mexican fruit flies (Diptera: Tephritidae) in traps baited with BioLures and AFF lures. Fla. Entomol. 89: 286-287.

Ryne, C., M. Ekeberg, P.-O. C. Olsson, P. G. Valeur, and C. Löfstedt. 2002. Water revisited: a powerful attractant for certain stored-product moths. Entomol. Exp. Appl. 103: 99-103.

Ryne, C., P. A. Nilsson, and M. T. Siva-Jothy. 2004. Dietary glycerol and adult access to water: effects on fecundity and longevity in the almond moth. J. Insect Physiol. 50: $429-434$.

SAS Institute. 2003. SAS system (version 9.1) for Windows SAS Institute, Cary, NC

Shani, A., and J. Clearwater. 2001. Evasion of mating disruption in Ephestia cautella (Walker) by increased pheromone production relative to that of undisrupted populations. J. Stored Prod. Res. 37: 237-252.

St-Germain, G., and R. Summerbell. 1996. Identifying filamentous fungi: a clinical laboratory handbook. Star Publishing Co., Belmont, CA.

Sweeney, J., J. M. Gutowski, J. Price, and P. De Groot. 2006. Effect of semiochemical release rate, killing agent, and trap design on detection of Tetropium fuscum (F.) and other longhorn beetles (Coleoptera: Cerambycidae). Environ. Entomol. 35: 645-654.

Thomas, D. B., T. C. Holler, R. R. Heath, E. J. Salinas, and A. L. Moses. 2001. Trap-lure combinations for surveillance of Anastrepha fruit flies (Diptera: Tephritidae). Fl. Entomol. 84: 344-351.

[USDA-ARS]. U.S. Department of Agriculture-Agricultural Research Service. 1986. Stored-grain insects. Agriculture Handbook 500. U.S. Department of Agriculture, Washington, DC.

Received 31 August 2007; accepted 26 December 2007. 